\title{
A Directive Ni Catalyst Overrides Conventional Site-Selectivity in Pyridine C-H Alkenylation
}

\author{
Tao Zhang, ${ }^{\dagger}$ Yu-Xin Luan, ${ }^{\dagger}$ Nelson Y. S. Lam,${ }^{\star}$ Jiang-Fei Li, ${ }^{\dagger}$ Yue Li, ${ }^{\dagger}$ Mengchun $\mathrm{Ye}^{* \dagger}$, Jin-Quan $\mathrm{Yu}^{* *}$ \\ †State Key Laboratory and Institute of Elemento-Organic Chemistry, College of Chemistry, Nankai University, Tianjin 300071, China. \\ \$The Scripps Research Institute, 10550 N. Torrey Pines Road, La Jolla, California 92037, USA.
}

\section{Supporting Information Placeholder}

\begin{abstract}
A remote $\mathrm{C} 3-\mathrm{H}$ activation of pyridine-containing substrates can be achieved with a directive Ni catalyst. The bifunctional NHC ligand incorporates an Al-binding side-arm that recruits and orients the substrate leading to the assembly of the requisite macrocyclophane transition state through reversible coordination. This assembly not only induces the reactivity of the otherwise unreactive $\mathrm{Ni}$ catalyst, but also overrides the intrinsic $\mathrm{C} 2 / \mathrm{C} 4$ electronic bias of the Al-bound pyridine substrate, allowing for the first time, the $\mathrm{C} 3$ alkenylation of a variety of pyridine and heteroarene substrates as the limiting reagent.
\end{abstract}

The ubiquity of $\mathrm{C}-\mathrm{H}$ bonds in organic molecules and their often-marginal chemical differences renders the site-selective activation of $\mathrm{C}-\mathrm{H}$ bonds an enduring challenge. ${ }^{1}$ The directing approach bearing a covalent bond between a directing group and a substrate has proved to be a particularly promising strategy for proximate and increasingly for remote $\mathrm{C}-\mathrm{H}$ bond activations (Type I, Scheme 1a), ${ }^{2}$ In particular, the importance of distance and geometric considerations for tuning the macrocyclophane transition state has been demonstrated for predictable remote $\mathrm{C}-\mathrm{H}$ activation. ${ }^{3,4}$ However, this covalent template strategy faces practical challenges that impede synthetic application, where stoichiometric template use and separate template attachment and removal steps are required. To address these challenges, a reversible template-substrate anchoring strategy has been developed (Type II, Scheme 1a). ${ }^{5}$ This strategy merges the role of template and ligand into a single bifunctional scaffold, renders the template catalytic and eliminates the extra steps required for template attachment/removal. Though attractive, this strategy has seen limited applications in the ability to catalyze wide-ranging functionalizations; success has so far been restricted to Ir-catalyzed remote $\mathrm{C}-$ $\mathrm{H}$ borylation through reversible interactions such as $\mathrm{H}$ bonding, ${ }^{6}$ ion pairing ${ }^{7}$ and Lewis acid coordination. ${ }^{8}$ In contrast, direct $\mathrm{C}-\mathrm{C}$ bond forming reactions of remote $\mathrm{C}-\mathrm{H}$ bonds has been scarcely explored, partly attributed to lower reactivity and harsher conditions required. Addressing this limitation, our group has recently achieved the first example of remote $\mathrm{C}-\mathrm{C}$ bond forming reaction via $\mathrm{Pd}-\mathrm{Pd}$ homobimetallic catalysis, furnishing remote $\mathrm{C}-\mathrm{H}$ alkenylation of relatively electron-rich arenes using the azine nitrogen as the template anchoring group (Scheme 1b). ${ }^{9}$ Despite a step forward, the requirements of high loadings of Pd, template, ligand, and super-stoichiometric amounts of metal oxidants for catalyst turnover offer much scope for practical improvement. Moreover, electron-deficient pyridine and related derivativeschallenging substrates widely encountered in natural products and pharmaceuticals - remain incompatible in such a reaction. Herein, we report a $\mathrm{Ni}-\mathrm{Al}$ heterobimetallic catalyst for the $\mathrm{C} 3-\mathrm{H}$ alkenylation of pyridines with alkynes, providing an atom-economical method for direct $\mathrm{C}-\mathrm{C}$ bond formation without the need for external oxidants (Scheme 1c). Importantly, this manifold enables the use of pyridines as the limiting reagent for the first time, allowing the late-stage $\mathrm{C} 3-\mathrm{H}$ alkenylation of pyridine motifs in complex molecules. A bifunctional NHC was identified as the critical ligand, which recruits and positions the substrate via $\mathrm{Al}$ anchorage to the vicinity of the Ni catalyst. This directive ligand not only enables catalytic reactivity through substrate and ligand binding, but also reverses the conventional $\mathrm{C} 2 / \mathrm{C} 4$ site-selectivity obtained in low-valent $\mathrm{Ni}$-catalyzed $\mathrm{C}-\mathrm{H}$ activation processes.

Scheme 1. Remote C-H Activation via Macrocyclophane Transition State

a) Remote $\mathrm{C}-\mathrm{H}$ activation via macrocyclophane transition State

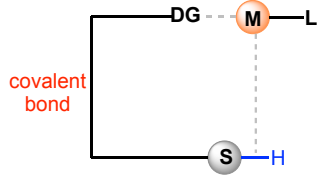

Type I: covalent template

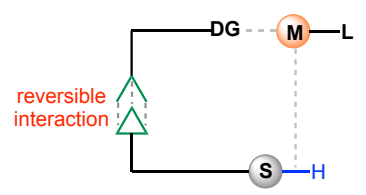

Type II: reversible template (limited to $C-B$ bond formation) b) Electron-rich arenes via homobimetallic assembly (previous work)

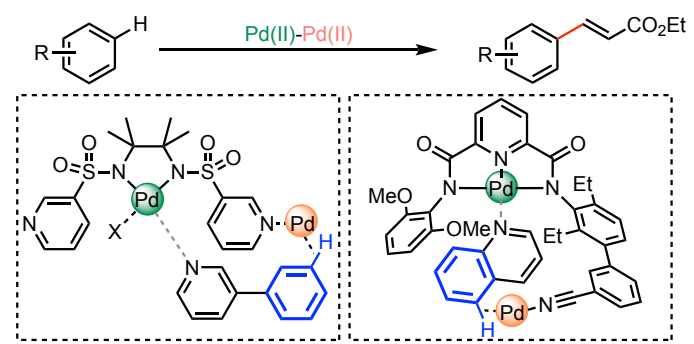

c) Electron-deficient pyridines via heterobimetallic assembly (this work)

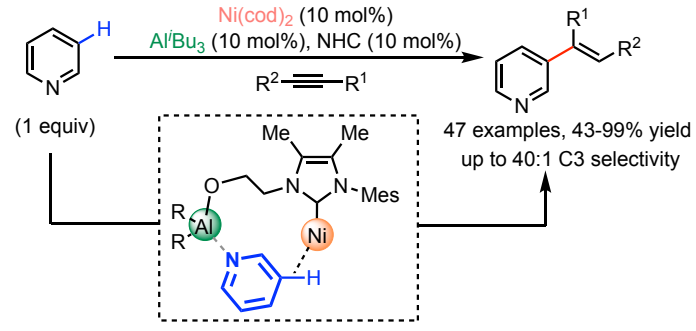


The C3-selective alkenylation of pyridine-containing heterocycles represents a desirable transformation in the realm of medicinal chemistry due to both its prevalence in pharmaceutical agents and its facile entry point to a range of functionalities (Scheme 2a). ${ }^{10,11}$ However, the strong $\sigma$-coordinative ability of pyridines often poison metal catalysts, rendering the development of catalytic processes a formidable challenge. In 2011, we reported a $\mathrm{Pd}(\mathrm{II})$-catalyzed $\mathrm{C} 3-\mathrm{H}$ alkenylation of pyridines, ${ }^{12,13}$ which gave high $\mathrm{C} 3$ selectivity arising from an electrophilic palladation process (Scheme 2b). However, a large excess of pyridine substrate (16 equivalents) was required to achieve reasonable reactivity. This drawback also rendered this reaction incompatible with the late-stage functionalization of complex pyridine-containing substrates, where the large excesses required poses unfavorable resource, cost and solubility issues in a synthetic setting. In pioneering studies by Nakao and Hiyama, ${ }^{14,15}$ coordination with $\mathrm{Al}$ Lewis acids was demonstrated to mask the pyridyl nitrogen, and polarized the pyridine ring to enhance the reactivity of $\mathrm{C} 2 / \mathrm{C} 4$ positions towards nucleophilic low-valent $\mathrm{Ni} \mathrm{C}-\mathrm{H}$ oxidative addition. Prompted by this finding, we envisioned that a bifunctional carbene ligand could coordinate to both $\mathrm{Ni}$ and $\mathrm{Al}$ and form a heterobimetallic catalyst ${ }^{16}$ directed towards the $\mathrm{C} 3(5)$ position, thus achieving the Type II template approach (Scheme 1) and reversing the conventional $\mathrm{C} 2 / \mathrm{C} 4$ selectivity (Scheme $2 \mathrm{c}$ ).

\section{Scheme 2. C3-Alkenylation of Pyridines ${ }^{a}$}

a) C3-alkenylated pyridines in bioactive molecules

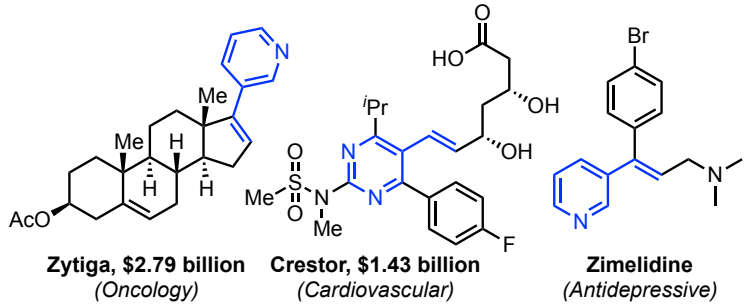

b) C3-Alkenylation of pyridines via Pd catalysis

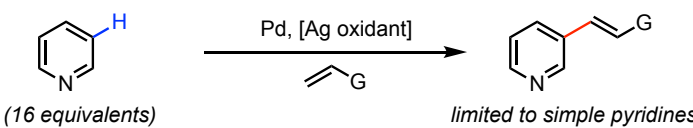

c) C3-Alkenylation of pyridines via low-valent $\mathrm{Ni}$ catalysis

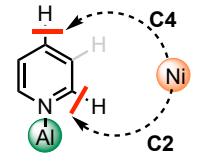

conventional $\mathrm{C} 2 / \mathrm{C} 4$ Nakao/Hiyama, Ong
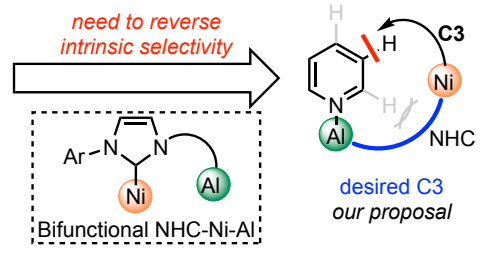

We selected non-substituted pyridine (1a) and oct-4-yne (2a) as the model substrate and coupling partner to explore the necessary ligands and reaction conditions for this transformation. Preliminary results showed that traditional phosphines and NHC ligands were poorly reactive and, as expected, delivered the alkenylated product at the $\mathrm{C} 2$ or $\mathrm{C} 4$ positions exclusively (Table $\mathrm{S} 1$ ). As expected, the in situ formation of NHCs from their precursors led to significant decrease in reactivity, attributed to the generation and deleterious coordination of ${ }^{t} \mathrm{BuOH}$ to the $\mathrm{Al}$ Lewis acid. To our delight, we found that ligand $\mathbf{L}_{\mathbf{1}}$ bearing a coordinating alkoxy group provided the desired mono-C3-alkenylated pyridine in moderate yields ( $33 \%$, Table S1), overruling the intrinsic $\mathrm{C} 2 / \mathrm{C} 4$ selectivity of the substrate. Notably, the observed reactivity for $\mathbf{L}_{1}$ could be obtained through the use of the imidazolium halide precursor, obviating the need for carbene pre-generation required in previous reports. ${ }^{15 a, b}$ Then we systematically surveyed a range of $\mathrm{Al}$ Lewis acids and varied the linker length on the ligand (Table
S3 and S6). We found that best results were obtained by using $\mathrm{Al}^{i} \mathrm{Bu}_{3}$ as the anchoring Lewis acid, in conjunction with a twocarbon alkoxy side-arm $\left(\mathbf{L}_{1}\right)$, improving the combined yield to $61 \%$ (Scheme 3). The importance of linker length was affirmed by the use of a homologated side-arm $\left(\mathbf{L}_{3}\right)$, which resulted in both a reduction in yield and selectivity. Notably, the use of unsubstituted aryl NHC ligand $\left(\mathbf{L}_{4}\right)$ was ineffective, inferring that the assembly of the putative macrocyclophane intermediate may be facilitated by conformational restriction. This observation was reinforced by the further incorporation of methyl groups onto the imidazolium backbone ( $\mathbf{L}_{6}$, Table S6), which elevated the yield to $64 \%$ (10:1, $\mathrm{C} 3$ :others). Additional tuning of the $\mathrm{NHC}$ aryl group revealed that the para-methoxy substitution was optimal $\left(\mathbf{L}_{\mathbf{1 0}}, 87 \%, c a .16: 1\right.$, C3:others, Scheme 3). Importantly, methylation of the coordinating alkoxy group completely shut down the reaction $\left(\mathbf{L}_{12}\right.$, Scheme $3),{ }^{17}$ demonstrating that Al coordination by the ligand side arm was crucial for both the reactivity and the selectivity of this process. Further mechanistic evidence validating such a threecomponent assembly process was obtained by ${ }^{1} \mathrm{H}$ NMR studies, which showed that 3-phenylpyridine, $\mathrm{AlMe}_{3}$ and ligand $\left(\mathbf{L}_{10}\right)$ formed a new complex demonstrated by marked downfield shifts of H2, H3, and H6 of 3-phenylpyridine (Page S13 and S14). In addition, heating the aforementioned three-component complex under the reaction conditions led to the $\mathrm{C} 3$-alkenylation product in $34 \%$ (Page S15), supporting the productive role this ternary complex plays in this reaction.

\section{Scheme 3. Ligand Optimization ${ }^{a}$}

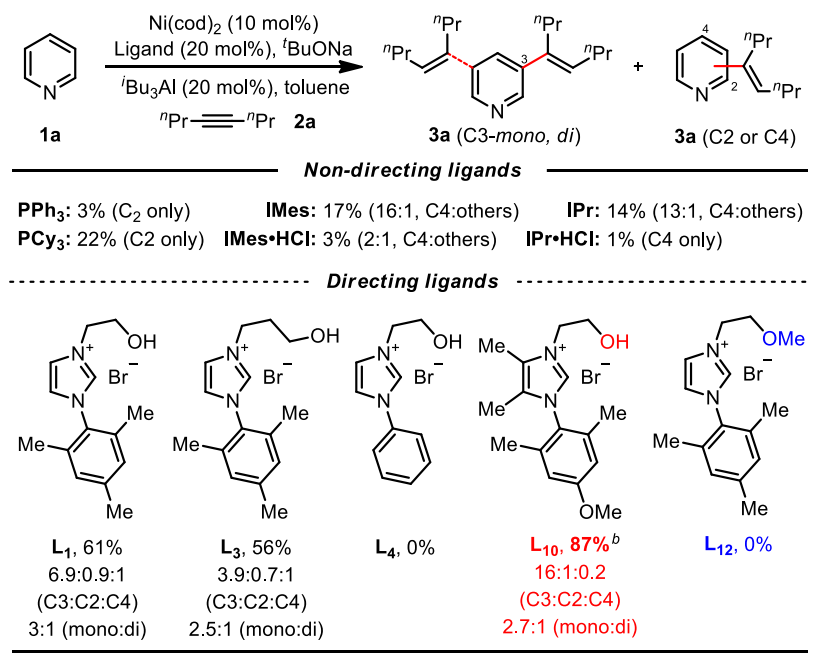

${ }^{a}$ Reaction conditions: $1 \mathrm{a}(0.20 \mathrm{mmol}), \mathbf{2 a}(0.6 \mathrm{mmol})$, toluene $(0.5$ $\mathrm{mL})$; $\mathrm{Ni}(\operatorname{cod})_{2}$, Ligand, ${ }^{t} \mathrm{BuONa}$ and toluene at $80{ }^{\circ} \mathrm{C}$ for $30 \mathrm{~min}$, then pyridine, $\mathrm{Al}^{i} \mathrm{Bu}_{3}$ and alkyne substrate at $100{ }^{\circ} \mathrm{C}$ under $\mathrm{N}_{2}$ for $12 \mathrm{~h}$; yield of isolated mixed isomers; ratio of isomers determined by ${ }^{1} \mathrm{H}$ NMR. ${ }^{b} \mathbf{L}_{10}(10 \mathrm{~mol} \%)$.

With the optimized conditions in hand, we proceeded to examine the scope of pyridines and other heteroarenes for this reaction (Scheme 4). Electron-donating substituents at C3 positions such as alkyls (3b, 3c, 3d), alkoxyl (3e) and amino groups (3f and $\mathbf{3 g}$ ) were compatible with the reaction, providing the corresponding products in $49 \%$ to $64 \%$ yield with the desired C5 selectivity (up to $30: 1$ ). It was pleasing to observe that increasing the electron density of the pyridine ring system tends to inhibit oxidative addition of the $\mathrm{Ni}(0)$ catalyst with $\mathrm{C}-\mathrm{H}$ bonds. As expected, electronwithdrawing groups such as $\mathrm{F}(\mathbf{3 h})$ and $\mathrm{CF}_{3}$ (3i) significantly elevated the yield to $91 \%(44: 1, \mathrm{C} 5: \mathrm{C} 4)$ and $99 \%(4: 1, \mathrm{C} 5: \mathrm{C} 4)$, respectively. Though highly reactive, decreased $\mathrm{C} 5$ selectivity was observed for $\mathbf{3 i}$ containing the $\mathrm{CF}_{3}$ group, attributed to poorer binding between the pyridyl group and the Al Lewis acid resultant 
of its strongly electron-withdrawing nature. A wide range of functionalities were well-tolerated in this reaction; $\mathbf{3 j}$ and $\mathbf{3 k}$ containing ester or amide groups both gave good yields and high $\mathrm{C} 5 \mathrm{se}-$ lectivity. In addition, aryl groups (3l-3p) bearing a range of functional groups such as methoxy (3n), silyl (3o) and boryl groups (3p) are tolerated, giving the desired products in $72-92 \%$ yields and excellent C5 selectivity (16:1 to 33:1). The presence of a C4phenyl group (3q) led to decreased reactivity and C3 selectivity, presumably owing to both its electron-donating effect as well as heightened steric hindrance. On the other hand, the smaller $\mathrm{C} 4$ fluoro group (3r) provided near-quantitative yield and high $\mathrm{C} 5$ selectivity (9:1). Consistent with the proposed coordination of pyridine with $\mathrm{Al}$ as a crucial mechanistic component, the presence of $\mathrm{C} 2$ substituents gave poorer reactivity and selectivity (3s and 3t). Notably, other azaheteroarenes were also compatible (3u to $\mathbf{3 x})$ : alkenylation of diazaheteroarenes such as pyridazine (3u) and pyrimidines (3v and 3w) afforded the desired products in $63-86 \%$ yields (6:1-25:1, C5:others); quinoline gave the alkenylated product in $72 \%$ yield, albeit with a lower selectivity $(1: 1, \mathbf{3 x})$ owing to poorer coordination with $\mathrm{Al}$ Lewis acid.

\section{Scheme 4. Scope of Pyridines ${ }^{a}$}

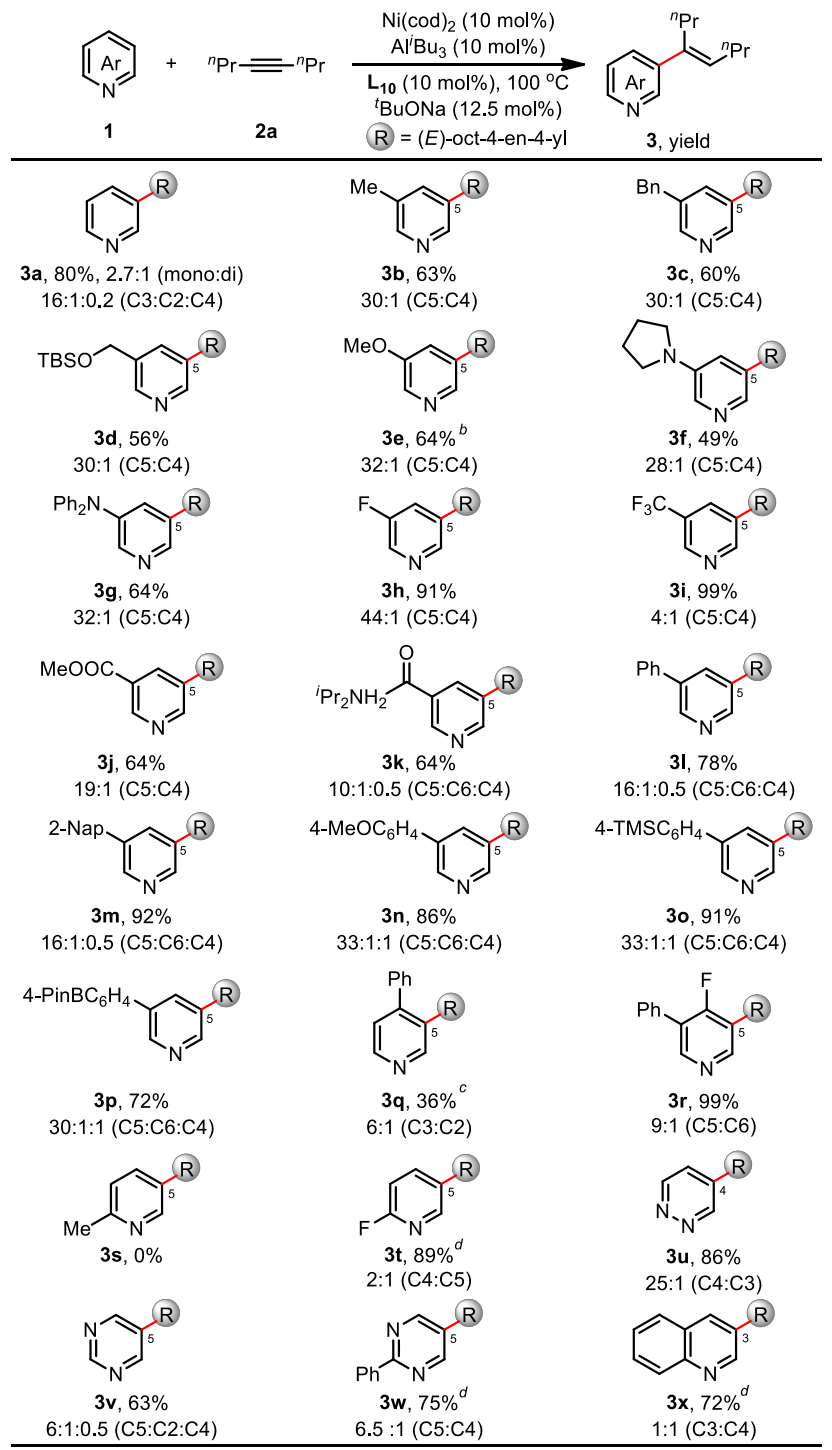

${ }^{a}$ Reaction conditions: $\mathbf{1}(0.40 \mathrm{mmol}), \mathbf{2 a}(1.20 \mathrm{mmol})$, toluene $(1.0$ $\mathrm{mL}) ; \mathrm{Ni}(\operatorname{cod})_{2}, \mathbf{L}_{\mathbf{1 0}},{ }^{t} \mathrm{BuONa}$ and toluene at $80{ }^{\circ} \mathrm{C}$ for $30 \mathrm{~min}$, then pyridine, $\mathrm{Al}^{i} \mathrm{Bu}_{3}$ and alkyne substrate at $100{ }^{\circ} \mathrm{C}$ under $\mathrm{N}_{2}$ for $12 \mathrm{~h}$; yield of isolated mixed isomers; ratio of isomers determined by
${ }^{1} \mathrm{H}$ NMR. ${ }^{b} \mathrm{Ni}(\mathrm{cod})_{2}(20 \mathrm{~mol} \%), \mathbf{L}_{10}(20 \mathrm{~mol} \%), \mathrm{Al}^{i} \mathrm{Bu}_{3}(20$ $\mathrm{mol} \%$ ), and ${ }^{t} \mathrm{BuONa}(25 \mathrm{~mol} \%) .{ }^{c} 140{ }^{\circ} \mathrm{C} .{ }^{d} \mathrm{Al}^{i} \mathrm{Bu}_{3}$ instead of $\mathrm{Al}-$ $\mathrm{Me}_{3}$.

The scope of alkyne coupling partners was next surveyed using 3-fluoropyridine (1h) as a model substrate. Considering the synthetic versatility of the olefin motif, it was pleasing to observe that a broad range of alkylalkynes was well-tolerated, affording the trisubstituted alkenylated products with excellent C5 selectivity (Scheme 5, >40:1 C5:others). Both symmetrical dialkylalkynes (4a to $\mathbf{4 e}$ ) and non-symmetrical alkylalkynes (4f to $\mathbf{4 h}$ ) afforded the corresponding products in $82-93 \%$ yields. For nonsymmetrical alkynes, the regiochemical outcomes were governed by the relative steric hindrance between the two alkyne substituents, with larger size differences giving higher alkene regioselectivity. As well, alkylalkynes bearing potentially acid and Lewis acid sensitive groups such as silanes (4i and $\mathbf{4 j}$ ) and silyl ethers (4k to 40 ) were all compatible substrates in this reaction.

\section{Scheme 5. Scope of Alkynes ${ }^{a}$}

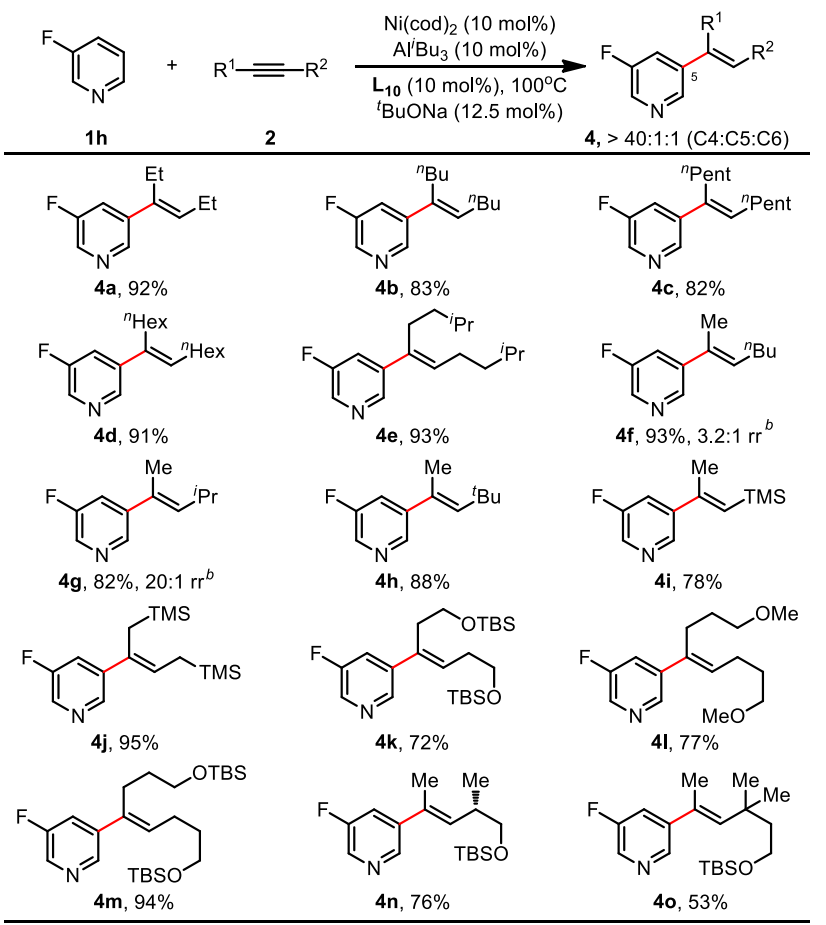

${ }^{a}$ Reaction conditions: $\mathbf{1 h}(0.40 \mathrm{mmol}), \mathbf{2}(1.20 \mathrm{mmol})$, toluene $(1.0 \mathrm{~mL}) ; \mathrm{Ni}(\operatorname{cod})_{2}, \mathbf{L}_{\mathbf{1 0}},{ }^{t} \mathrm{BuONa}$ and toluene at $80{ }^{\circ} \mathrm{C}$ for $30 \mathrm{~min}$, then pyridine, $\mathrm{Al}^{\mathrm{i}} \mathrm{Bu}_{3}$ and alkyne substrate at $100{ }^{\circ} \mathrm{C}$ under $\mathrm{N}_{2}$ for $12 \mathrm{~h}$; yield of isolated products; ${ }^{b}$ Regioisomer ratio of alkenes determined by ${ }^{1} \mathrm{H}$ NMR.

In contrast to previously reported $\mathrm{C}-\mathrm{H}$ olefination of pyridines, ${ }^{12}$ this newly-developed catalyst allows for the use of pyridine substrates as the limiting agent, thus opening new avenues for the efficient late-stage modification of heterocycle-containing bioactive molecules (Scheme 6). To demonstrate this, we applied our $\mathrm{C}-\mathrm{H}$ alkenylation reaction to a range of nicotinic acid-derived complex molecules, such as (-)-menthol (5a), (-)-borneol (5b), diacetonefructose $(\mathbf{5 c}),(-)$-Corey lactone diol $(\mathbf{5 d})$, and cholesterol (5e). Gratifyingly, the reactions proceeded smoothly, providing the desired products in 43-79\% yield and with high C5 selectivity (11:1-32:1). Medicinally relevant compounds were also competent in this process; azabicyclic compound (5f), representing an important class of agent active in the central nervous system, was alkenylated in 60\% yield (26:1 C5:others). Abiraterone (5g), an anticancer drug, was alkenylated in 65\% yield (34:1 C5:others). In 
addition, bioactive steroid hormones such as estrone (5h) and estradiol (5i) were also suitable substrates, providing the corresponding alkenylated products in $88 \%$ and $89 \%$ yield, respectively, both with high C5 selectivity (15:1-30:1).

In conclusion, we have developed a bifunctional $\mathrm{Ni}$ catalyst that allows, for the first time, the $\mathrm{C} 3(5)$-selective $\mathrm{C}-\mathrm{H}$ alkenylation of pyridine-containing hetereocycles as the limiting reagent. As the alkene functionality could be readily derivatized, the broad scope and synthetic practicality of this reaction could enable the facile access of diverse C3(5)-functionalized motifs bearing a range of carbon oxidation states. We determined that the assembly of a putative macrocyclophane intermediate through reversible $\mathrm{Al}$ coordination was crucial to enable both catalyst reactivity and site-selectivity. As a testament to the strength of the directing effect, the ligand allows for the Ni catalyst to override the intrinsic electronic activation of the $\mathrm{C} 2$ and $\mathrm{C} 4$ and achieve the selective metalation at the $\mathrm{C} 3-\mathrm{H}$ bond of pyridines. This process further validates the applicability of a merged ligand-template strategy in $\mathrm{C}-\mathrm{H}$ activation, where we anticipate these design principles applied to a wider range of remote functionalization processes.

Scheme 6. Late-Stage Alkenylation of Pyridine-Containing Bioactive Molecules ${ }^{a}$

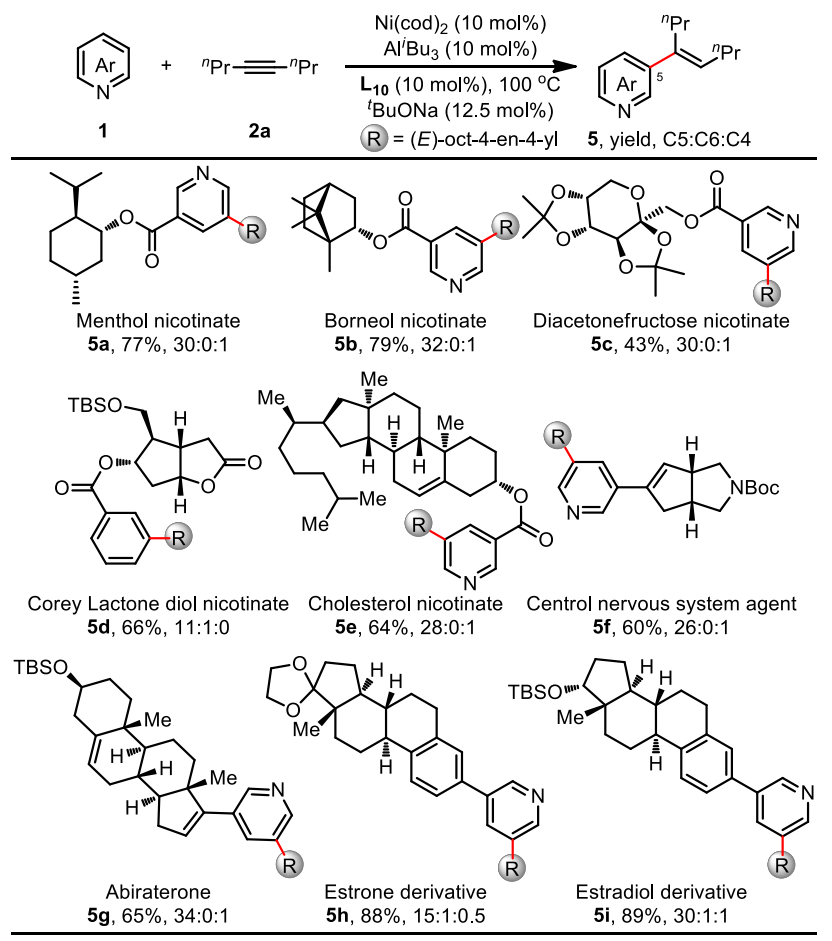

${ }^{a}$ Reaction conditions: $\mathbf{1}(0.40 \mathrm{mmol}), \mathbf{2 a}(1.20 \mathrm{mmol})$, toluene $(1.0 \mathrm{~mL}) ; \mathrm{Ni}(\operatorname{cod})_{2}, \mathbf{L}_{\mathbf{1 0}},{ }^{t} \mathrm{BuONa}$ and toluene at $80{ }^{\circ} \mathrm{C}$ for $30 \mathrm{~min}$, then pyridine, $\mathrm{Al}^{i} \mathrm{Bu}_{3}$ and alkyne substrate at $100{ }^{\circ} \mathrm{C}$ under $\mathrm{N}_{2}$ for $12 \mathrm{~h}$; yield of isolated mixed isomers; ratio of $\mathrm{C} 5 / \mathrm{C} 6 / \mathrm{C} 4$ determined by ${ }^{1} \mathrm{H}$ NMR. ${ }^{b} \mathrm{Ni}(\mathrm{cod})_{2}(20 \mathrm{~mol} \%), \mathbf{L}_{\mathbf{1 0}}(20 \mathrm{~mol} \%), \mathrm{Al}^{i} \mathrm{Bu}_{3}$ (20 mol\%), ${ }^{t} \mathrm{BuONa}(25 \mathrm{~mol} \%)$.

\section{ASSOCIATED CONTENT}

\section{Supporting Information}

The Supporting Information is available free of charge on the ACS Publications website. Experimental procedures and spectral data for all new compounds (PDF). Metrical parameters for the structure of $\mathbf{L}_{\mathbf{1 0}}$ are available free of charge from the Cambridge Crystallographic Data Centre under reference number CCDC 1434263.

\section{AUTHOR INFORMATION}

\section{Corresponding Author}

*mcye@nankai.edu.cn, yu200@scripps.edu

\section{Notes}

The authors declare no competing financial interests.

\section{ACKNOWLEDGMENT}

We thank the National Natural Science Foundation of China (91856104, 21871145 and 21672107) and "the Fundamental Research Funds for the Central Universities" (63191601) for financial support. We also gratefully acknowledge The Scripps Research Institute, the Lindemann Trust (N.Y.S.L.), and the NIH ((National Institute of General Medical Sciences grant R01GM102265) for financial support.

\section{REFERENCES}

(1) For selected reviews on site-selective activation of $\mathrm{C}-\mathrm{H}$ bonds, see: (a) Neufeldt, S. R.; Sanford, M. S. Controlling Site Selectivity in Palladium-Catalyzed $\mathrm{C}-\mathrm{H}$ Bond Functionalization. Acc. Chem. Res. 2012, 45, 936-946. (b) Mahatthananchai, J.; Dumas, A. M.; Bode, J. W. Catalytic Selective Synthesis. Angew. Chem. Int. Ed. 2012, 51, 10954-10990. (c) Kuhl, N.; Hopkinson, M. N.; Wencel-Delord, J.; Glorius, F. Beyond Directing Groups: Transition-Metal-Catalyzed $\mathrm{C}-\mathrm{H}$ Activation of Simple Arenes. Angew. Chem. Int. Ed. 2012, 51, 10236-10254. (d) Tobisu, M.; Chatani, N. Remote Control by Steric Effects. Science 2014, 343, 850-851. (e) Funken, N.; Zhang, Y.-Q.; Gansäuer, A. Regiodivergent Catalysis: A Powerful Tool for Selective Catalysis. Chem. Eur. J. 2017, 23, 19-32. (f) Ping, L.; Chung, D. S.; Bouffard, J.; Lee, S. Transition metal-catalyzed site- and regio-divergent $\mathrm{C}-\mathrm{H}$ bond functionalization. Chem. Soc. Rev. 2017, 46, 4299-4328.

(2) For selected reviews on chelated proximate $\mathrm{C}-\mathrm{H}$ bond activations, see: (a) Chen, X.; Engle, K. M.; Wang, D.-H.; Yu, J.-Q. Palladium(II)Catalyzed $\mathrm{C}-\mathrm{H}$ Activation/C-C Cross-Coupling Reactions: Versatility and Practicality. Angew. Chem. Int. Ed. 2009, 48, 5094-5115. (b) Colby, D. A.; Bergman, R. G.; Ellman, J. A. Rhodium-Catalyzed C-C Bond Formation via Heteroatom-Directed $\mathrm{C}-\mathrm{H}$ Bond Activation. Chem. Rev. 2010, 110, 624-655. (c) Lyons, T. W.; Sanford, M. S. PalladiumCatalyzed Ligand-Directed $\mathrm{C}-\mathrm{H}$ Functionalization Reactions. Chem. Rev. 2010, 110, 1147-1169. (d) Ackermann, L. Carboxylate-Assisted Transition-Metal-Catalyzed $\mathrm{C}-\mathrm{H}$ Bond Functionalizations: Mechanism and Scope. Chem. Rev. 2011, 111, 1315-1345. (e) Colby, D. A.; Bergman, R. G.; Ellman, J. A. Rhodium-Catalyzed C-C Bond Formation via Heteroatom-Directed C-H Bond Activation. Chem. Rev. 2010, 110, 624-655. (f) Chen, Z.; Wang, B.; Zhang, J.; Yu, W.; Liu, Z.; Zhang, Y. Transition Metal-Catalyzed C-H Bond Functionalizations by the Use of Diverse Directing Groups. Org. Chem. Front. 2015, 2, 1107-1295. (g) Newton, C. G.; Wang, S.-G.; Oliveira, C. C.; Cramer, N. Catalytic enantioselective transformations involving $\mathrm{C}-\mathrm{H}$ bond cleavage by transition-metal complexes. Chem. Rev. 2017, 117, 8908-8976. (h) Saint-Denis, T. G.; Zhu, R.-Y.; Chen, G.; Wu, Q.-F.; Yu, J.-Q. Enantioselective C( $\left.\mathrm{sp}^{3}\right)-\mathrm{H}$ bond activation by chiral transition metal catalysts. Science 2018 359, eaao4798.

(3) For selected reviews on chelated remote $\mathrm{C}-\mathrm{H}$ bond activations, see: (a) Li, J.; De Sarkar, S.; Ackermann, L. meta- and para-Selective C-H Functionalization by $\mathrm{C}-\mathrm{H}$ Activation. Top. Organomet. Chem. 2015, 55, 217-257. (b) Sharma, R.; Sharma, U. Remote C-H bond activation/transformations: A continuous growing synthetic tool; Part II. Catal. Rev. 2018, 60, 497-565. (c) Mihai, M. T.; Genov, G. R.; Phipps, R. J. Access to the meta position of arenes through transition metal catalysed $\mathrm{C}-\mathrm{H}$ bond functionalisation: a focus on metals other than palladium. Chem. Soc. Rev. 2018, 47, 149-171. (d) Dey, A.; Sinha, S. K.; Achar, T. K.; Maiti, D. Accessing Remote meta- and para-C( $\left(\mathrm{sp}^{2}\right)-\mathrm{H}$ Bonds with Covalently Attached Directing Groups. Angew. Chem., Int. Ed. 2019, 58, 10820-10843. (e) Shao, Q.; Wu, K.; Zhuang, Z.; Qian, S.; Yu, J.-Q. From $\mathrm{Pd}(\mathrm{OAc})_{2}$ to Chiral Catalysts: The Discovery and Development of Bifunctional Mono-N-Protected Amino Acid Ligands for Diverse C-H Functionalization Reactions. Acc. Chem. Res. 2020, 53, 833-851. (f) Meng, G.; Lam, N. Y. S.; Lucas, E. L.; Saint-Denis, T. G.; Verma, P.; Chekshin, N.; 
$\mathrm{Yu}, \mathrm{J} . \mathrm{Q}$. Achieving site-selectivity for $\mathrm{C}-\mathrm{H}$ activation processes based on distance and geometry: A carpenter's approach. J. Am. Chem. Soc. 2020, 142, 10571-10591.

(4) For selected examples on chelated remote $\mathrm{C}-\mathrm{H}$ bond activations, see: (a) Leow, D.; Li, G.; Mei, T.-S.; Yu, J.-Q. Activation of remote meta$\mathrm{C}-\mathrm{H}$ bond assisted by an end-on template. Nature 2012, 486, 518-522. (b) Hofmann, N.; Ackermann, L. Meta-Selective C-H Bond Alkylation with Secondary Alkyl Halides. J. Am. Chem. Soc. 2013, 135, 5877-5884. (c) Wang, X.-C.; Gong, W.; Fang, L.-Z.; Zhu, R.-Y.; Li, S.; Engle, K. M.; Yu, J.-Q. Ligand-Enabled meta-C-H Activation Using a Transient Mediator. Nature 2015, 519, 334-338. (d) Phipps, R. J.; Gaunt, M. J. A MetaSelective Copper-Catalyzed C-H Bond Arylation. Science 2009, 323, 1593-1597. (e) Bag, S.; Patra, T.; Modak, A.; Deb, A.; Maity, S.; Dutta, U.; Dey, A.; Kancherla, R.; Maji, A.; Hazra, A.; Bera, M.; Maiti, D. Remote para $\mathrm{C}-\mathrm{H}$ Functionalization of Arenes by a D-Shaped Biphenyl TemplateBased Assembly. J. Am. Chem. Soc. 2015, 137, 11888-11891. (f) Das, S.; Incarvito, C. D.; Crabtree, R. H.; Brudvig, G. W. Molecular recognition in the selective oxygenation of saturated $\mathrm{C}-\mathrm{H}$ Bonds by a dimanganese catalyst. Science 2006, 312, 1941-1943.

(5) For relevant reviews, see: (a) Gandeepan, P.; Ackermann, L. Transient Directing Groups for Transformative $\mathrm{C}-\mathrm{H}$ Activation by Synergistic Metal Catalysis. Chem 2018, 4, 199-222. (b) Davis, H. J.; Phipps, R. J. Harnessing non-covalent interactions to exert control over regioselectivity and site-selectivity in catalytic reactions. Chem. Sci. 2017, 8, 864-877. (c) Kim, D. S.; Park, W.-J.; Jun, C.-H. Metal-Organic Cooperative Catalysis in $\mathrm{C}-\mathrm{H}$ and $\mathrm{C}-\mathrm{C}$ Bond Activation. (d) Rousseau, G.; Breit, B. Removable Directing Groups in Organic Synthesis and Catalysis. Angew. Chem. Int. Ed. 2011, 50, 2450-2494.

(6) For examples on H-bonding interaction, see: (a) Roosen, P. C.; Kallepalli, V. A.; Chattopadhyay, B.; Singleton, D. A.; Maleczka, R. E.; Smith, M. R. III Outer-Sphere Direction in Iridium C-H Borylation. $J$. Am. Chem. Soc. 2012, 134, 11350-11353. (b) Preshlock, S. M.; Plattner, D. L.; Maligres, P. E.; Krska, S. W.; Maleczka, R. E. Jr.; Smith, Milton R. III A Traceless Directing Group for C-H Borylation. Angew. Chem. Int. Ed. 2013, 52, 12915-12919. (c) Kuninobu, Y.; Ida, H.; Nishi, M.; Kanai, M. A meta-selective $\mathrm{C}-\mathrm{H}$ borylation directed by a secondary interaction between ligand and substrate. Nat. Chem. 2015, 7, 712-717. (d) Davis, H. J.; Genov, G. R.; Phipps, R. J. Meta-Selective C-H Borylation of Benzylamine, Phenethylamine and Phenylpropylamine-Derived Amides Enabled by a Single Anionic Ligand. Angew. Chem. Int. Ed. 2017, 56, 1335113355. (e) Lu, X.; Yoshigoe, Y.; Ida, H.; Nishi, M.; Kanai, M.; Kuninobu, Y. Hydrogen Bond-Accelerated meta-Selective C-H Borylation of Aromatic Compounds and Expression of Functional Group and Substrate Specificities. ACS Catal. 2019, 9, 1705-1709. (f) Genov, G. R.; Douthwaite, J. L.; Lahdenperä, A. S. K.; Gibson, D. C.; Phipps, R. J. Enantioselective remote $\mathrm{C}-\mathrm{H}$ activation directed by a chiral cation. Science $\mathbf{2 0 2 0}$, $367,1246-1251$

(7) For examples on ion-pair or electrostatic interaction, see: (a) Davis, H. J.; Mihai, M. T.; Phipps, R. J. Ion pair-directed regiocontrol in transition-metal catalysis: A meta-selective $\mathrm{C}-\mathrm{H}$ borylation of aromatic quaternary ammonium salts. J. Am. Chem. Soc. 2016, 138, 12759-12762. (b) Chattopadhyay, B.; Dannatt, J. E.; Andujar-De Sanctis, I. L.; Gore, K. A.; Maleczka, R. E.; Singleton, D. A.; Smith, M. R. III Ir-Catalyzed orthoBorylation of Phenols Directed by Substrate-Ligand Electrostatic Interactions: A Combined Experimental/in Silico Strategy for Optimizing Weak Interactions. J. Am. Chem. Soc. 2017, 139, 7864-7871. (c) Mihai, M. T.; Phipps, R. J. Ion-Pair-Directed meta-Selective C-H Borylation of Aromatic Quaternary Ammonium Salts. Synlett 2017, 28, 1011-1017.

(8) For examples on Lewis acid coordination, see: (a) Bisht, R.; Chattopadhyay, B. Formal Ir-Catalyzed Ligand-Enabled Ortho and Meta Borylation of Aromatic Aldehydes via in Situ-Generated Imines. J. Am. Chem. Soc. 2016, 138, 84-87. (b) Li, H. L.; Kuninobu, Y.; Kanai, M. Lewis Acid-base interaction-controlled ortho-selective $\mathrm{C}-\mathrm{H}$ borylation of aryl sulfides. Angew. Chem. Int. Ed. 2017, 56, 1495-1499. (c) Hoque, M. E.; Bisht, R.; Haldar, C.; Chattopadhyay, B. Noncovalent interactions in Ir-catalyzed $\mathrm{C}-\mathrm{H}$ activation: L-shaped ligand for para-selective borylation of aromatic esters. J. Am. Chem. Soc. 2017, 139, 7745-7748. (d) Bisht, R.; Hoque, M. E.; Chattopadhyay, B. Amide effects in C-H activation: Noncovalent interactions with L-shaped ligand for meta borylation of aromatic amides. Angew. Chem. Int. Ed. 2018, 57, 15762-15766. (e) Yang, L.; Uemura, N.; Nakao, Y. meta-Selective C-H borylation of benzamides and pyridines by an iridium-Lewis acid bifunctional catalyst. J. Am. Chem. Soc. 2019, 141, 7972-7979.
(9) (a) Zhang, Z.; Tanaka, K.; J.-Q. Yu, Remote site-selective C-H activation directed by a catalytic bifunctional template. Nature 2017, 543, 538-542. (b) Shi, H.; Lu, Y.; Weng, J.; Bay, K. L.; Chen, X.; Tanaka, K.; Verma, P.; Houk, K. N.; Yu, J.-Q. Differentiation and functionalization of remote $\mathrm{C}-\mathrm{H}$ bonds in adjacent positions. Nat. Chem. 2020, 12, 399-404.

(10) Vitaku, E.; Smith, D. T.; Njardarson, J. T. Analysis of the structural diversity, substitution patterns, and frequency of nitrogen heterocycles among U.S. FDA approved pharmaceuticals. J. Med. Chem. 2014, 57, 10257-10274.

(11) For relevant reviews on $\mathrm{C}-\mathrm{H}$ activation of pyridines, see: (a) $\mathrm{Mu}-$ rakami, K.; Yamada, S.; Kaneda, T.; Itami, K. C-H Functionalization of Azines. Chem. Rev. 2017, 117, 9302-9332. (b) Stephens, D. E.; Larionov, $\mathrm{O}$. V. Recent advances in the $\mathrm{C}-\mathrm{H}$ functionalization of the distal positions in pyridines and quinolines. Tetrahedron 2015, 71, 8683-8716. (c) Iwai, T.; Sawamura, M. Transition-Metal-Catalyzed Site-Selective C-H Functionalization of Quinolines beyond C2 Selectivity. ACS Catal. 2015, 5, 5031-5040. (d) Nakao, Y. Transition-Metal-Catalyzed C-H Functionalization for the Synthesis of Substituted Pyridines. Synthesis 2011, 20, 3209-3219. (e) Nakao, Y. Hydroarylation of Alkynes Catalyzed by Nickel. Chem. Rec. 2011, 11, 242-251.

(12) (a) Ye, M.; Gao, G.-L.; Yu, J.-Q. Ligand-promoted C-3 selective $\mathrm{C}-\mathrm{H}$ olefination of pyridines with Pd catalysts. J. Am. Chem. Soc. 2011 133, 6964-6967. For related work, see: (b) Cong, X.; Tang, H.; Wu, C.; Zeng, X. Role of mono-N-protected amino acid ligands in palladium(II)catalyzed dehydrogenative Heck reactions of electron-deficient (hetero)arenes: experimental and computational studies. Organometallics 2013, 32, 6565-6575.

(13) (a) Takagi, J.; Sato, K.; Hartwig, J. F.; Ishiyama, T.; Miyaura, N. Iridium-catalyzed $\mathrm{C}-\mathrm{H}$ coupling reaction of heteroaromatic compounds with bis(pinacolato)diboron: regioselective synthesis of heteroarylboronates. Tetrahedron Lett. 2002, 43, 5649-5651. (b) Mkhalid, I. A. I.; Conventry, D. N.; Albesa-Jove, D.; Batsanov, A.S.; Howard, J. A. K.; Perutz, R. N.; Marder, T. B. Ir-catalyzed borylation of C-H bonds in Ncontaining heterocycles: Regioselectivity in the synthesis of heteroaryl boronate esters. Angew. Chem. Int. Ed. 2006, 45, 489-491. (c) Murphy, J. M.; Liao, X.; Hartwig, J. F. Meta Halogenation of 1,3-Disubstituted Arenes via Iridium-Catalyzed Arene Borylation. J. Am. Chem. Soc. 2007 , 129, 15434-15435. (d) Li, B.-J.; Shi, Z.-J. Ir-catalyzed highly selective addition of pyridyl $\mathrm{C}-\mathrm{H}$ bonds to aldehydes promoted by triethylsilane. Chem. Sci. 2011, 2, 488-493. (e) Ye, M.; Gao, G.-L.; Edmunds, A. J. F.; Worthington, P. A.; Morris, J. A.; Yu, J.-Q. Ligand-promoted C3-selective arylation of pyridines with Pd catalysts: gram-scale synthesis of $( \pm$ preclamol. J. Am. Chem. Soc. 2011 133, 19090-19093. (f) Dai, F.; Gui, Q.; Liu, J.; Yang, Z.; Chen, X.; Guo, R.; Tan, Z. Pd-catalyzed C3-selective arylation of pyridines with phenyl tosylates. Chem. Commun. 2013, 49, 4634-4636. (g) Larsen, M. A.; Hartwig, J. F. Iridium-Catalyzed $\mathrm{C}-\mathrm{H}$ Borylation of Heteroarenes: Scope, Regioselectivity, Application to LateStage Functionalization, and Mechanism. J. Am. Chem. Soc. 2014, 136, 4287-4299. (h) Cheng, C.; Hartwig, J. F. Iridium-Catalyzed Silylation of Aryl C-H Bonds. J. Am. Chem. Soc. 2015, 137, 592-595. (i) Wübbolt, S.; Oestreich, M. Catalytic Electrophilic C-H Silylation of Pyridines Enabled by Temporary Dearomatization. Angew. Chem. Int. Ed. 2015, 54, 15876-15879. (j) Jiao, J.; Murakami, K.; Itami, K. Palladium-catalyzed CH Arylation of Pyridines with Aryl Triflates. Chem. Lett. 2016, 45, 529531. (k) Yamada, S.; Murakami, K.; Itami, K. Regiodivergent CrossDehydrogenative Coupling of Pyridines and Benzoxazoles: Discovery of Organic Halides as Regio-Switching Oxidants. Org. Lett. 2016, 18, 2415-2418. (1) Yang, L.; Uemura, N.; Nakao, Y. meta-Selective C-H Borylation of Benzamides and Pyridines by an Iridium-Lewis Acid Bifunctional Catalyst. J. Am. Chem. Soc. 2019, 141, 7972-7979. (m) Zhang, W.-B.; Yang, X.-T.; Ma, J.-B.; Su, Z.-M.; Shi, S.-L. Regio- and enantioselective $\mathrm{C}-\mathrm{H}$ cyclization of pyridines with alkenes enabled by a nickel $/ N$ heterocyclic carbene catalysis. J. Am. Chem. Soc. 2019, 141, 5628-5634. (n) Xie, H.; Shao, Y.; Gui, J.; Lan, J.; Liu, Z.; Ke, Z.; Deng, Y.; Jiang, H.; Zeng, W. Co(II)-Catalyzed Regioselective Pyridine C-H Coupling with Diazoacetates. Org. Lett. 2019, 21, 3427-3430.

(14) Nakao, Y.; Kanyiva, K. S.; Hiyama, T. A strategy for C-H activation of pyridines: Direct $\mathrm{C}-2$ selective alkenylation of pyridines by nickel/Lewis acid catalysis. J. Am. Chem. Soc. 2008, 130, 2448-2449.

(15) For relevant works, see: (a) Tsai, C.-C.; Shih, W.-C.; Fang, C.-H.; Li, C.-Y.; Ong, T.-G.; Yap, G. P. A. Bimetallic nickel aluminun mediated para-selective alkenylation of pyridine: Direct observation of $\eta^{2}, \eta^{1}$ pyridine $\mathrm{Ni}(0)-\mathrm{Al}(\mathrm{III})$ intermediates prior to $\mathrm{C}-\mathrm{H}$ Bond Activation. J. Am. Chem. Soc. 2010, 132, 11887-11889. (b) Nakao, Y.; Yamada, Y.; 
Kashihara, N.; Hiyama, T. Selective C-4 alkylation of pyridine by nickel/Lewis acid catalysis. J. Am. Chem. Soc. 2010, 132, 13666-13668. (c) Lee, W.-C.; Chen, C.-H.; Liu, C.-Y.; Yu, M.-S.; Lina, Y.-H.; Ong, T.-G. Nickel-catalysed para- $\mathrm{CH}$ activation of pyridine with switchable regioselective hydroheteroarylation of allylarenes. Chem. Commun. 2015, 51, 17104-17107. (d) Singh, V.; Nakao, Y.; Sakaki, S.; Deshmukh, M. M. Theoretical Study of Nickel-Catalyzed Selective Alkenylation of Pyridine: Reaction Mechanism and Crucial Roles of Lewis Acid and Ligands in Determining the Selectivity. J. Org. Chem. 2017, 82, 289-301.

(16) For relevant reviews on NHC ligands, see: (a) Thongpaen, J.; Manguin, R.; Basle, O. Chiral N-heterocyclic carbene ligands enable asymmetric $\mathrm{C}-\mathrm{H}$ bond functionalization. Angew. Chem. Int. Ed. 2020, 59, 10242-10251. (b) Zhao, Q.; Meng, G.; Nolan, S. P.; Szostak, M. $\mathrm{N}$-Heterocyclic carbene complexes in $\mathrm{C}-\mathrm{H}$ activation reactions. Chem. Rev. 2020, 120, 1981-2048.

(17) As expected, the use of the imidazolium halide precursor to $\mathbf{L}_{5}$ led to the complete shut-down of reactivity in a manner similar to the use of $\mathrm{IPr} \cdot \mathrm{HCl}$ and IMes $\cdot \mathrm{HCl}$, where the formed ${ }^{t} \mathrm{BuOH}$ deleteriously reacts with the Al Lewis acid. This result also signifies the importance of the free hydroxyl group in the directive NHC ligands, where it preferentially reacts with the Al Lewis acid and modulates the reactivity such that further reaction with ${ }^{t} \mathrm{BuOH}$ is inhibited. Unfortunately, our attempt at generating and employing the free carbene from $\mathbf{L}_{5}$ was unsuccessful due to the instability of the formed carbene species.

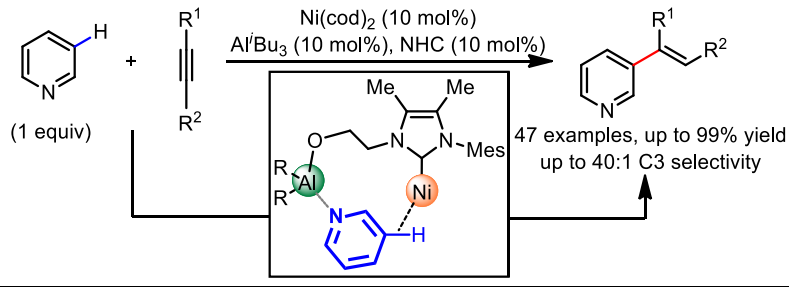

